

\title{
The role of economic factors, including the level of tuition, in individual university participation decisions in Canada*
}

\author{
DAVID R. JOHNSON \& FIONA T. RAHMAN \\ Wilfrid Laurier University
}

\begin{abstract}
The study uses individual data from the Canadian Labour Force Survey to consider economic factors in university participation decisions by persons aged 17-24 from 1976 to 2003 . The level of real tuition is one economic factor that may affect the university participation decision. There is also regional variation in the opportunity cost of university attendance; in the reduction in the probability of unemployment after obtaining a university degree; and in the proportion of university budgets used for financial support of students. In addition, there is some national variation by gender and over time in the return to a university education. This study finds that higher tuition levels in the 1990s did reduce the probability of university participation by persons aged 17,18 or 19 relative to a provincespecific trend increase in university participation. Before drawing a policy conclusion from this result, it would be necessary to consider what the trend terms represent in the university participation decision.
\end{abstract}

* The authors would like to thank Michelle Edwards and Bo Wandschnieder at the TriUniversity Data Centre at the University of Guelph for their help, Mike Veall for his very useful econometric advice, as well as the referees and participants at the 2004 Canadian Economics Association meetings for their comments. 


\begin{abstract}
RESUMÉ
Cette étude utilise des données individuelles de l'Enquête sur la main-d'œuvre au Canada, afin d'examiner les facteurs économiques qui entrent en jeu dans la décision prise, de 1976 à 2003, par des personnes de 17 à 24 ans, de s'inscrire dans une université. Le niveau du coût réel des études est un facteur économique qui peut affecter cette décision. On trouve aussi des variations régionales dans le « coût d'opportunité » de la fréquentation universitaire, dans la réduction de la probabilité de se retrouver au chômage après l'obtention d'un diplôme universitaire, et dans la proportion du budget consacrée par les universités à l'aide financière aux étudiants. On trouve, en outre, quelques variations, à l'échelle nationale, selon le sexe et selon le laps de temps écoulé avant le retour aux études universitaires. Cette étude constate que l'augmentation des frais d'études, dans les années 1990, a effectivement réduit la probabilité que des personnes de 17,18 ou 19 ans fréquentent l'université, par rapport à une tendance spécifiquement provinciale à l'accroissement de la fréquentation. Avant d'en tirer des conclusions quant à la politique à suivre, il faudrait examiner les composants de cette tendance pour déterminer en quoi celleci influence la décision de fréquenter l'université.
\end{abstract}

\title{
INTRODUCTION
}

Many papers address the question: What is the effect, if any, of increases in university tuition on university enrolment decisions by Canadians? One innovation in this study is to use the individual responses in the Labour Force Survey (LFS) to consider the university participation decision in Canada. ${ }^{1}$ A very significant advantage of the LFS over other surveys is a large sample of individuals in each province in every year from 1976 to 2003 . The second innovation in this study is to pay more attention to economic factors beyond tuition that play a role in the decision to attend university. There is national variation by gender and over time in the observed return to university attendance. There is regional and gender variation in the opportunity cost of university attendance and in employment prospects with and without a university degree. This variation

The Canadian Journal of Higher Education

Volume XXXV, No. 3, 2005 


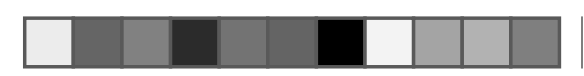

has not been fully exploited in previous studies of the choices made by young Canadians to go to university. The disadvantage of using the LFS is also clear. Relatively little is known about the family and other personal characteristics of the respondents. Only the age, gender, highest educational status, family type, current educational status and current labour market activity of each respondent is known. Other surveys, with much shorter time spans and much smaller samples, ask questions that provide more information about the family background of the individuals. ${ }^{2}$

Our study finds that economic variables play a role in the university participation decision. A higher payoff to university increases the probability of participation, but this effect is observed primarily through higher female relative to male participation at university. Females have a higher relative return to obtaining a university degree. A higher opportunity cost reduces the probability of university participation but the effect is weak. When a prospective university student observes a larger gap between the unemployment rate for those with a completed high school degree and those with a university degree, university participation rises. There is also some very modest evidence that when universities spend more money on student support, the probability of participation rises. In our paper, as in the rest of the literature, the extent of financial support to current students is not well measured.

Much research in this area, reviewed in Section 2, asks whether higher tuition fees reduce university participation. We find that when province-specific trend variables are included in the model, higher tuition fees reduce participation. This reduction in university participation is a reduction relative to a large increase in university participation driven by positive coefficients on trend variables in all provinces except Quebec. The reduction in participation associated with higher tuition is strongest for potential participants aged 17,18 or 19, the age at which young Canadians are most likely to enter university. Real university tuition in Canada rose by approximately $\$ 2000$ between 1989 and 2003, whereas from 1976 to 1988 real tuition fees were roughly unchanged. ${ }^{3}$. The estimated reduction in university participation rates of 17, 18 and 19 year-old Canadians lies between 1 and 3 percentage points per one-thousand dollar increase in tuition. University participation rose dramatically in Canada from 1989 to 2003 and indeed for the entire period from 1976 to 2003. Outside of Quebec (where the trend was negative) the trend increase in university

The Canadian Journal of Higher Education Volume XXXV, No. 3, 2005 
participation averaged about 0.4 percentage points per year in the sample period. Over 27 years, this trend effect raised participation rates by 11 percentage points. In addition, the benefits of university participation in terms of a reduced unemployment rate for university graduates increased from 1976 to 2003 and the opportunity cost of attending university fell by approximately $\$ 2000$ dollars for females and $\$ 3000$ for males between 1976 and 2003. Any reduction in university participation due to higher tuition was more than offset by other factors (primarily the trends) that increased university participation. The research in the paper reports estimates of the size of these various effects. Without specifying the reasons behind the trend increases in university participation, it is not possible to conclude whether the various provincial decisions to increase tuition were good or bad policy decisions. The exercise in this paper is to quantify the size of the reduction in enrolment due to higher tuition if other factors are held constant. To re-emphasize, these other factors were not constant.

The paper proceeds as follows. Section 2 is a brief review of previous studies of the relationship between the level of tuition at universities and the enrolment decision. Section 3 describes the variables used in this study. Section 4 discusses the methodological issues that arise in using the LFS. Section 5 presents the results. There is a brief conclusion followed by two appendices. One appendix lists, in detail, the variables in the models estimated. The other appendix lists the data sources.

\section{Previous literature}

In most jurisdictions and institutions a mix of public funding and private fees pays for university. ${ }^{4}$ Much of the existing literature focuses on the role of the level of tuition as a key economic factor in the decision to attend university. There are numerous American studies looking at the effect of tuition fees on post-secondary participation. American studies emphasize variation across states in the fee charged for access to publicsector post-secondary institutions and relate that variation to variation in post-secondary enrolment rates across states. 45 studies are reviewed in Leslie and Brinkman (1988). A further 20 studies are reviewed in Heller (1997) with an update in Heller (1999). A number of issues are identified: What is the population eligible for enrolment? How should we treat part time students? What post-secondary institutions are included? What are the costs of post-secondary attendance beyond the direct tuition costs

The Canadian Journal of Higher Education

Volume XXXV, No. 3, 2005 


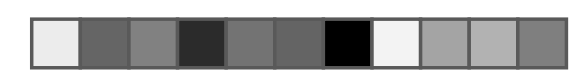

and various other mandatory fees? What is the role of student aid? These studies typically find that in states with higher tuition at state universities, the participation rate in post-secondary education is lower. Are the results of studying Canadian data similar?

Canada, with its variation in university fees across provinces, has been the subject of a significant amount of research, on the effect of tuition levels, and, to a lesser degree, other economic factors, on postsecondary access. Looker and Lowe (2001) as well as Junor and Usher $(2002,2004)$ summarize a great deal of Canadian research into the factors affecting the decision to participate in post-secondary education. Levin (1990) considers, but does not statistically investigate variation in fees and participation across Canadian provinces. Fortin (2005) uses a joint sample of participation rates in Canadian provinces and American states to establish a negative relationship between aggregate enrolment rates by geographic unit and fees. Drolet (2005) uses the data in the Survey of Labour and Income Dynamics (SLID) to construct aggregate participation rates grouping individuals by income, region and parental education groups from 1993 to 2001 . There is no evidence of change in participation rates in these groups in spite of considerable regional variation in tuition changes.

Most Canadian studies look at individual data. Butlin (1996) uses a single year of school leavers in Canada in 1995 and does not find a cross-section relationship between lower tuition and higher participation. Tomkowicz, Shipley and Oulette (2003) use the responses to the Youth-inTransition Survey to conclude that finances are perceived as a significant barrier to post-secondary education. But Rivard and Raymond (2004) cannot find, using the same survey, any statistical relationship between higher tuition and reduced participation. Frenette (2005) uses data from the Survey of Labour and Income Dynamics (SLID) in the 1990s to discover, using geographic distance as a proxy for increased cost of attendance, potential students further away from a university or college are less likely to attend. There are both provincial and year dummy variables in the analysis but no explicit tuition variable. Coelli (2004) also uses the SLID data from 1993 to 2001 to measure links between tuition, university and college tuition and post-secondary educational choices. In the full sample, there is no statistically significant effect of higher university tuition on the probability of university attendance. When the sample is split into 
low, medium and high income groups (approximately 500 observations across Canada in each group), then higher tuition does reduce enrolment in the lowest income group but has no effect on enrolment decisions in the middle and high income groups.

Christofides, Cirello and Hoy (CCH) (2001) use the household responses to a large-scale long-running survey, the Survey of Consumer Finances (SCF). Questions were posed to Canadian families in 1975, 1977, 1979, 1981, 1982, 1983 and, at the time of $\mathrm{CCH}$, in all the years from 1984-1993. The proportion of households with children aged 18-24 and who are attending post-secondary education is calculated by income quintile. It is very clear that children from higher income households are more likely to attend post-secondary education in all time periods. There is a clear upward trend in post-secondary attendance in all income quintiles over the time period. $\mathrm{CCH}$ cannot reject the null hypothesis that the positive and significant coefficient on a time trend is the same for all income quintiles. In a period of rising real tuition ending in 1993, there is no measurable difference in the behaviour of lower income families. A real tuition variable, constructed for each province as real tuition at the university in the province's largest city was added to the models, and, to quote (CCH, page 198), "Tuition never has the anticipated negative and significant coefficient." This statement is true for both the whole sample and for a sub-sample of low-income families. Corak, Lipps and Zhao (CLZ, 2003) also use the SCF data and are able to reproduce the participation rates in $\mathrm{CCH}$. Rather than investigate the role of economic factors directly, CLZ estimate, for each year of the data, a relationship between enrolment and family income and ask if these relationships are stable over time. Although there is a period in the early 1990s where the correlation between enrolment and family income rises, the correlation returns to its historical level in the last half of the decade. Their conclusion: higher tuition has not reduced accessibility to university in an obvious way.

Neill (2005) in a recent study quite similar to our study, also makes use of the individual data from the LFS. Using the LFS master files, Neill is able to identify the highest level of education of parents for about 60 percent of individuals aged 18-24. These persons either actually reside with their parents or are temporarily away at a post-secondary institution and are included as residing with their parents in the survey. Studying the

The Canadian Journal of Higher Education Volume XXXV, No. 3, 2005 


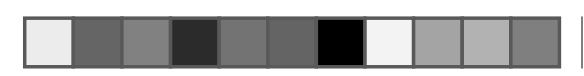

behaviour of the 60 percent of the 18-24 year old group that are linked to parents is one important contribution of Neill's paper. In Neill, there is a very strong positive effect of higher parental education on enrolment and a very strong negative effect on enrolment if someone in the economic family is unemployed. These are the family variables available in the 60 percent of the sample where parental links exist. The parental education variable is missing from our study because we use the Public Use rather than the Master File of the LFS. This is an advantage of Neill's paper over our paper. The second major contribution of Neill's study is that the tuition variable is treated as endogenous. In our study it is treated as exogenous. Using a set of instruments that include the political party in power by province, Neill finds higher tuition reduces enrolments more in the setting where tuition is treated as endogenous. Our study confirms her important result in a slightly simpler setting with different control variables.

Neill (2005) and our paper both use the LFS data to investigate the university participation decision in Canada. We have a better treatment of the variable related to the eligibility of individuals to attend university. The individuals in the LFS have a variable reporting the highest completed level of education. This variable allowed us to create a powerful proxy variable related to the likelihood that the observed individual is eligible to attend university. We have better measures of the opportunity cost of university attendance. Our use of the LFS data, with some additional information on wages, allows interesting calculations of both the opportunity cost of attending university and the longer-term benefits of obtaining a degree. We created a forward-looking measure of the reduction in unemployment expected by an individual obtaining a university degree. One contribution of our paper over Neill is the more complete set of other economic factors that might affect enrolment decisions in our study.

As already stated, the major disadvantage of the LFS is that very little is known about the family background of the respondent in either the Public Use or Master File of the LFS. The advantages of the LFS may or may not outweigh its disadvantage. It is sensible to use different data sources and different models to improve our understanding of the university participation decision. Our study, Neill's (2005) study and Coelli's (2004) Studies based on the Survey of Labour and Income Dynamics (SLID) all provide evidence that contradicts Junor and Usher's (2004, page 104) statement: "The evidence to support the notion that price - that is, tuition 
and forgone income - is a barrier to access is, in an aggregate sense, slim to non-existent." All three studies find some statistically significant financial barriers to access using aggregate data.

\section{Variables used in the analysis}

The variables are classified in four ways: a measure of participation in a university education; the benefits of participation in university; the costs of participation in university; and dummy, trend and interaction variables associated with the geographic unit where the individual lives as well as limited background data on the individual.

\section{Measuring participation in post-secondary education}

The LFS data are re-organized by geographic region in Canada. The Atlantic provinces are grouped together as one unit, all other provinces form individual geographic units, for convenience, we often call them provinces. The LFS reports if a respondent is a student or a non-student and identifies the respondent's highest level of education. Analysis revealed, for each region, a fairly conventional full-time university participation rate. A university participant is defined as either a full time university student or as a person with at least one university degree (or both). ${ }^{5}$ University participation rates were calculated for two groups. The first group is all persons aged 17-24. The second group is all persons aged 17-24 excluding persons currently in elementary or secondary school and excluding persons not currently in school who have completed less than 9 or 10 years of schooling. In most provinces, rates for the two groups diverge. The participation rate at full-time university as a proportion of the population more likely to be eligible rises over time. Participation in Quebec has a different structure. ${ }^{6}$

\section{The benefits of participation in university}

The non-monetary benefits of university attendance, whatever they may be, are not directly measured. The study uses two measures of the economic benefits of university participation. In both cases, a prospective student compares persons with a university degree to persons without a degree who have completed or nearly completed high school. One variable (not presented in graphical form) is the difference between the

The Canadian Journal of Higher Education Volume XXXV, No. 3, 2005 
unemployment rate, by gender, of persons aged 25-39 with a high school education minus the unemployment rate of the group with a university degree. The other variable, presented in Figure 1, illustrates a measure of the additional earnings available to university degree holders since 1976. Others have done most of the large amount of work needed to calculate this variable. Bar-Or, Burbidge, Magee and Robb (1995, updated 2002, 2003) calculate the ratio of median earnings, by gender, of university graduates to high school graduates (full-time workers aged 25-64) in Canada using data from the Survey of Consumer Finances, the Survey of Labour and Income Dynamics and Labour Force Survey for various years. ${ }^{7}$ The variable is calculated nationally for both men and for women. The LFS is used to update this variable from 2001 to 2003 . The missing years from the various data sets are interpolated as averages between adjacent years. A three-year backward looking moving average of the ratio of the median university earnings to the median high school earnings was then calculated. It is striking that throughout the period the payoff to university attendance is much higher for females than for males. The payoff to university attendance for males increased slightly over the sample period.

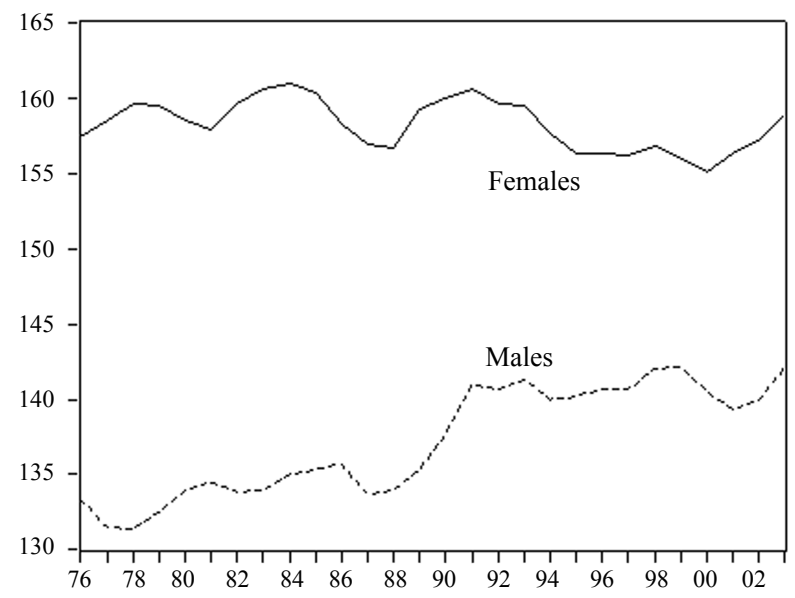

Figure 1. The ratio of wages with a university degree to those with 11,12 or 13 years of high school: persons aged 25-64 


\section{Measuring the costs of university attendance}

Two elements of the cost of attending university are measured. The opportunity cost of university attendance is (average hourly earnings of persons with 11, 12 or 13 years of high school) multiplied by (average hours worked per week) multiplied by (36 weeks) multiplied by (1 - unemployment rate of persons aged 17-24 with 11,12 or 13 years of high school) averaged over the 12 months preceding the current academic year. ${ }^{8}$ All these variables are directly reported in the LFS after 1997 and are calculated for each region and for each gender. Before 1997, the LFS contains no information about average hourly earnings of any individuals. Average hourly earnings in the tavern industry in that province were compared to the average hourly earnings reported in the LFS for persons who have completed high school after 1997. For the 6 overlapping years and the 7 regions, the two wages are similar. Figure 2 plots our measure of the opportunity cost of university attendance for men and women in each of the 7 regions. Several comments are in order. The spike in the opportunity cost of university attendance in British Columbia is associated with a very high value of the average hourly wage earned at taverns in one year. This data point was checked and is unexplained in the present analysis. ${ }^{9}$ There are less dramatic fluctuations. The opportunity cost of university attendance measured in constant (1992) dollars falls, more for males than females, systematically from 1976 to 2003. In regional or national recessions, as the unemployment rate increases, the opportunity cost of university attendance falls.

The other cost variable, the direct policy variable, is the measure of tuition and fees. Statistics Canada has collected various data on tuition and compulsory fees in undergraduate arts programs by province since 1976 . Tuition is re-expressed in real or constant (1992) dollar terms using the provincial Consumer Price Indexes. ${ }^{10}$ Figure 3 shows that in all regions except Quebec real tuition was constant or only rising slightly from 1976 to 1989. In Quebec real tuition fell over that period. In the period from 1990 to 2003, real tuition increased the most in Alberta and the least in Quebec. The recent upsurge in tuition in British Columbia is particularly noticeable.

For individual students, the tuition cost "should be" net of any scholarships or subsidies. Such a correction is not available at the individual level in the LFS. The subsidy element of student loan programs

The Canadian Journal of Higher Education

Volume XXXV, No. 3, 2005 

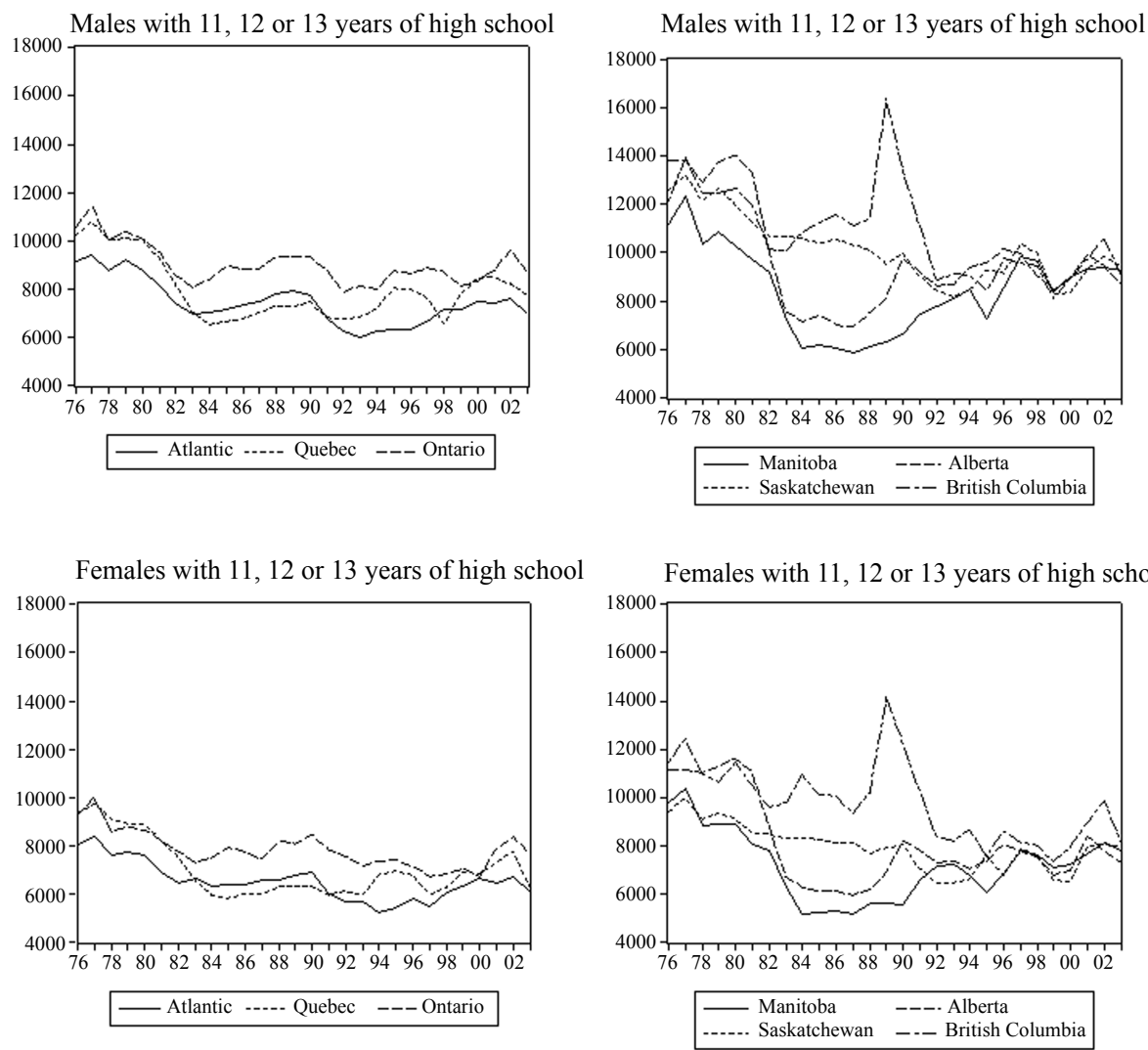

Figure 2. The opportunity cost (\$1992) of university attendance
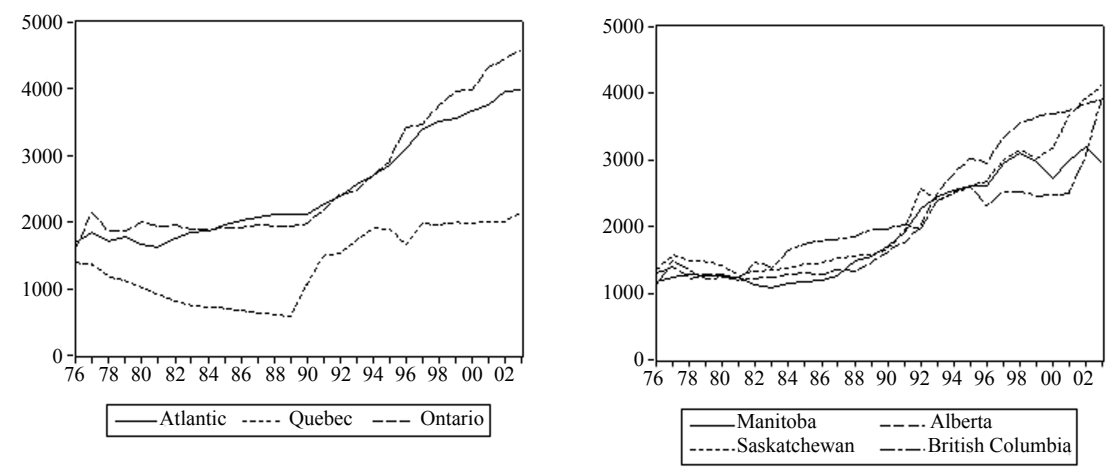

Figure 3. Real Tuition Fees (\$1992) 
is particularly difficult to measure since it will depend on complex rules around the interest rate and the required structure of repayments that determine the subsidy element implicit in these loans. There are also substantial subsidies built into the tax system. Figure 4 presents some readily available data on student support. ${ }^{11}$ The proportion of total university expenditure used for student support, by region, is available only from the 1976-77 to 2001-02 academic years. The proportion of university budgets spent on student support rises slightly over time. Student support in Alberta far surpasses the other provinces using this, not very precise, measure of student support.
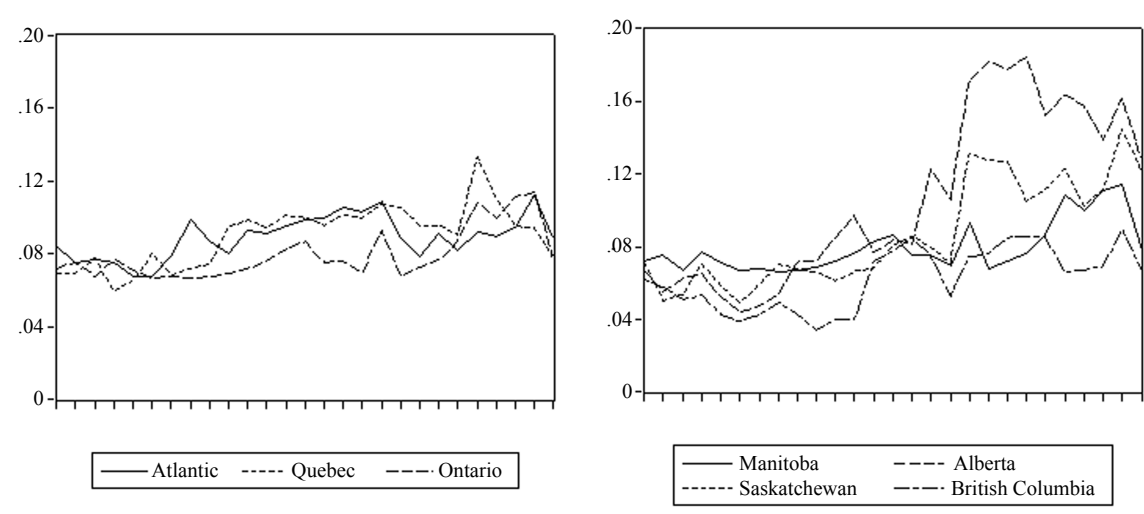

Figure 4. The Proportion of University Expenditures Used for Student Support 1976-2001

\section{Background variables associated with a respondent}

As already noted, the disadvantage of the LFS is the lack of descriptive data on the individual respondent. There are only five background variables associated with each respondent in the Public Use file. The province of residence is identified. The respondent's highest completed level of education is identified however the categories change after 1989. The respondent's current educational activity is recorded. The respondent's gender known. In addition, age is known as $17-19,20-21$ or $22-24$ rather than simply aged 17-24.

This background information identifies, in many cases, when an individual respondent is not likely to be eligible for post-secondary

The Canadian Journal of Higher Education Volume XXXV, No. 3, 2005 
participation. If before or after 1990, the respondent's highest educational attainment is reported as either $0-8$ years of school or 9 or 10 years of school then it is very unlikely that this individual is academically eligible for university. ${ }^{12}$ Some of the persons in the latter category (or the next category for years of school) are also currently full-time high school students and also not eligible in either time period. Both pre and post 1990, the individuals identified above have a variable called ELIGIBLE set equal to zero. In the pre-1990 sample, all other individuals in the sample have the value of ELIGIBLE set equal to one. It is very important to note that before 1990 some but not all persons with 11, 12 or 13 years of schooling will actually not be secondary school graduates and are actually unlikely to be eligible for university. Even some secondary school graduates in that group would not have high enough grades to gain a place in university. Thus not all persons with the value of ELIGIBLE set equal to one are actually eligible for university. They are just much more likely to be academically eligible to attend university.

After 1990 the survey measure of the highest level of education attainment changes. An additional category of highest educational achievement makes a distinction between individuals with some upperlevel secondary education from those who are a Grade 11, 12 or 13 (it varies by province) secondary school graduate. Thus after 1990, the persons with some secondary school education but who are NOT secondary school graduates also have the value of ELIGIBLE set equal to zero. Then persons who are high school graduates have the variable ELIGIBLE set equal to one. Some of these persons are not eligible for university, they may not have high enough grades to obtain admission. ELIGIBLE is an important variable in our analysis. It captures substantial changes in the average level of secondary school educational achievement in society between 1976 and 2003. It also captures the substantial increase in high school participation by the youngest age group over the same period. We are interested in the participation in university after controlling for changes in the decision to remain in high school and for changes in high school completion rates.

Coefficients on dummy variables associated with the province capture any effects on the enrolment decision that are constant over time and common to that geographic unit. A province-specific trend variable increases by one unit per year in that province and is zero in other provinces. The coefficient on such a variable measures the effects of other unknown 
variables that increase or decrease university attendance in the country or in a specific region in a systematic way over time. ${ }^{13}$ The coefficients on the other economic variables then measure the effect of these variables on the participation decision relative to trend. Although such variables are very common in models describing the decision to attend university, it is more difficult to interpret the coefficients on the variables in models with trends. ${ }^{14}$ Table 2 presents models of university participation with and without province-specific trend variables so that the role of the trend variables is better understood.

\section{RESULTS}

If the respondent is a full-time university student or already has a university degree (or both) in the month of October in the survey year, the dependent variable $\left(\mathrm{P}_{\mathrm{i}, \mathrm{j}, \mathrm{t}}\right)$ takes on a value of unity, if not, the dependent variable takes on a value of zero. ${ }^{15}$ One econometric issue is how to model a binary dependent variable. Three approaches could be taken: a linear probability model, a logit specification or a probit specification, see Kennedy (2003, Chapter 15) or Greene (2003, Chapter 21) for more extensive discussions of each approach. We present results from only the linear probability specification. ${ }^{16}$

The linear probability model writes

$$
P_{i, j, t}=\$ X_{i, j, t}+e_{i, j, t}
$$

where each element of the coefficient vector $\$$ represents the effect of a unit change of the corresponding element of a vector $\mathrm{X}$ on the probability that the respondent " $i$ " in year" $t$ " in province " $j$ " is either a full time university student or already has a university degree. ${ }^{17}$ In writing (1), the individual is treated as making or having made a decision on whether he or she wants to participate in university based on the values of the $\mathrm{X}$ variable relevant to that individual. The simplest assumption to make in estimating and interpreting equation (1) is that if the individual wants a university place at the prevailing tuition rate, such a place is available somewhere in the province. ${ }^{18}$ There is a second econometric complication in using the Labour Force Survey. The individual respondents are not a random sample of Canadians in that month. Rather they are selected randomly from a multilayer stratified sample so that, when the appropriate weights are applied to each observation, the correct estimates of the mean values of variables for various strata and sub-strata are obtained. ${ }^{19}$ In order to calculate statistics

The Canadian Journal of Higher Education

Volume XXXV, No. 3, 2005 


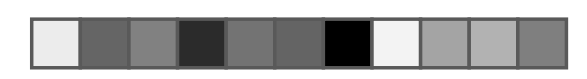

for small geographic units, the Labour Force Survey over-samples small geographic units (think of a small province like Prince Edward Island where a simple random sample would yield no observations in most cases) and under-samples large geographic units (think of Metropolitan Toronto). The LFS includes the information needed to adjust for this stratification so that the $\$$ coefficients represent decisions by the population of Canadians in specific categories. The standard errors on the elements of the vector \$ are estimated with robust estimation techniques that take the weights and potential heteroscedasticity into account. What factors significantly affect the probability of a person aged 17-24 living in Canada between 1976 and 2003 participating in university?

The coefficient estimates measuring the effects of various factors in the university participation decision are presented in 5 tables of results in the working paper presentation available from the author. Two tables are presented here. Two data sets are always used, a data set that represents all Canadians aged 17 to 24 and a smaller data set that represents Canadians aged 17, 18 or 19, the ages at which most Canadians first enter university.

Table 1 presents the average probability of university participation, by region for three time periods, the full sample, and the periods before and after (including) 1990. In the latter period, real tuition rose rapidly but university participation also increased. The standard errors around the probability that the individual in the region in a time period is participating in university are estimated robustly. It is clear that there are strong regional differences and strong region-specific age differences in university participation.

Table 2 presents the crucial relationships between participation and the level of real tuition, relationships that carry through to more extensive analysis presented in Tables 3,4 and 5 in the working paper. The table presents information on two parallel specifications and for two samples, all persons aged 17-24 and the subset of persons aged 17, 18 or 19. The upper portion of the table presents specifications without trend variables; the lower portion presents the same specifications including province-specific trend variables. The positive coefficients on these trend variables are all statistically significant and are presented, by region, in last row of Table 2. Factors that change slowly over time in each province are increasing the probability of university participation in all regions and all age groups except for the group of 17-19 year olds in Quebec. In that province a 


\begin{tabular}{|c|c|c|c|c|c|c|c|}
\hline \multicolumn{8}{|c|}{$\begin{array}{l}\text { Table } 1 \\
\text { University Participation Rates by Region and Time Period from the LFS }\end{array}$} \\
\hline \multicolumn{8}{|c|}{ All persons aged 17-24 } \\
\hline $\begin{array}{l}\text { Time } \\
\text { Period }\end{array}$ & Atlantic & QC & ON & MB & SK & $\mathrm{AB}$ & $\mathrm{BC}$ \\
\hline $\begin{array}{c}\text { Full } \\
\text { Sample }\end{array}$ & $\begin{array}{l}0.187 \\
(.001)\end{array}$ & $\begin{array}{l}0.142 \\
(.001)\end{array}$ & $\begin{array}{l}0.183 \\
(.001)\end{array}$ & $\begin{array}{l}0.193 \\
(.002)\end{array}$ & $\begin{array}{l}0.177 \\
(.002)\end{array}$ & $\begin{array}{l}0.149 \\
(.001)\end{array}$ & $\begin{array}{l}0.147 \\
(.002)\end{array}$ \\
\hline $\begin{array}{c}\text { Before } \\
1990\end{array}$ & $\begin{array}{l}0.142 \\
(.001)\end{array}$ & $\begin{array}{l}0.114 \\
(.001)\end{array}$ & $\begin{array}{l}0.149 \\
(.001)\end{array}$ & $\begin{array}{l}0.165 \\
(.003)\end{array}$ & $\begin{array}{l}0.135 \\
(.002)\end{array}$ & $\begin{array}{c}0.124 \\
(.002)\end{array}$ & $\begin{array}{c}0.112 \\
(.002)\end{array}$ \\
\hline $\begin{array}{c}\text { After } \\
1990\end{array}$ & $\begin{array}{l}0.243 \\
(.002)\end{array}$ & $\begin{array}{c}0.179 \\
(.002)\end{array}$ & $\begin{array}{l}0.221 \\
(.002)\end{array}$ & $\begin{array}{c}0.228 \\
(.004)\end{array}$ & $\begin{array}{l}0.230 \\
(.003)\end{array}$ & $\begin{array}{l}0.176 \\
(.003)\end{array}$ & $\begin{array}{c}0.180 \\
(.003)\end{array}$ \\
\hline \multicolumn{8}{|c|}{ Persons aged 17,18 or 19} \\
\hline $\begin{array}{l}\text { Time } \\
\text { Period }\end{array}$ & Atlantic & QC & $\mathrm{ON}$ & MB & SK & $\mathrm{AB}$ & $\mathrm{BC}$ \\
\hline $\begin{array}{c}\text { Full } \\
\text { Sample }\end{array}$ & $\begin{array}{l}0.179 \\
(.002)\end{array}$ & $\begin{array}{l}0.052 \\
(.001)\end{array}$ & $\begin{array}{l}0.112 \\
(.001)\end{array}$ & $\begin{array}{l}0.178 \\
(.004)\end{array}$ & $\begin{array}{l}0.158 \\
(.003)\end{array}$ & $\begin{array}{l}0.116 \\
(.002)\end{array}$ & $\begin{array}{l}0.115 \\
(.003)\end{array}$ \\
\hline $\begin{array}{c}\text { Before } \\
1990\end{array}$ & $\begin{array}{l}0.135 \\
(.002)\end{array}$ & $\begin{array}{l}0.048 \\
(.001)\end{array}$ & $\begin{array}{l}0.093 \\
(.002)\end{array}$ & $\begin{array}{l}0.160 \\
(.005)\end{array}$ & $\begin{array}{l}0.125 \\
(.003)\end{array}$ & $\begin{array}{l}0.104 \\
(.003)\end{array}$ & $\begin{array}{l}0.090 \\
(.003)\end{array}$ \\
\hline $\begin{array}{l}\text { After } \\
1990\end{array}$ & $\begin{array}{l}0.233 \\
(.003)\end{array}$ & $\begin{array}{l}0.056 \\
(.002)\end{array}$ & $\begin{array}{l}0.132 \\
(.002)\end{array}$ & $\begin{array}{l}0.200 \\
(.006)\end{array}$ & $\begin{array}{l}0.198 \\
(.005)\end{array}$ & $\begin{array}{l}0.129 \\
(.004)\end{array}$ & $\begin{array}{l}0.129 \\
(.004)\end{array}$ \\
\hline
\end{tabular}

Note. These participation rates are estimated using the Labour Force Survey for the month of October. The standard errors around the probability of university attendance in this province or region appear in parentheses below. These are corrected for sampling weights.

reform of the secondary school process created the CEGEP system and altered the trend relationships for the youngest age group. One possible interpretation of the positive coefficients on the trend terms in the other provinces is that, as Canadian family incomes rose over time, attendance at university was part of an overall increase in consumption. The presence or absence of the trend terms makes a huge difference in the estimated coefficients on the tuition variable. The estimated relationships between real tuition and participation are positive and significantly different from zero in the upper portion of Table 2 where there are no trend terms. The same coefficients are negative and significantly different from zero in the lower portion of Table 2 when trend terms are included. This is a

The Canadian Journal of Higher Education

Volume XXXV, No. 3, 2005 


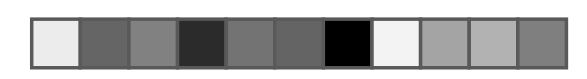

central element of the description of the university participation process from 1976 to 2003 in Canada. There is a strong increase over time in both real tuition and university participation. Any negative effect of tuition on participation is relative to this strong upward trend.

The interpretation of the coefficients on tuition in the lower portion of Table 2 is that, relative to a within-province trend, individuals in a province with a higher real level of tuition have a lower probability of university participation. Using the full sample, a $\$ 1000$ increase in real tuition in the current year, reduces the probability that a person aged 17-24 participates (participated) in university by 0.0133 or by 1.33 percentage points. If we focus on the behaviour of the younger age group on the lower right-hand side of Table 2 then the current-year magnitude of the current-year tuition effect on participation is twice as large, 0.0287 or 2.87 percentage points per $\$ 1000$ increase in real tuition. However, in Table 2, the effects of tuition on participation are measured ignoring the influence of other economic factors that would be expected to increase university participation. Before the influence of the other economic variables is considered, Table 2 considers several other aspects of the university participation decision in Canada.

In the first line of Table 2, the only variable outside of provincial dummy variables and the tuition variable is a dummy variable equal to one if the respondent is female. The coefficients on the provincial dummy variables are not presented (they can be inferred from Table 1). The coefficient on female is either 0.0271 (or 0.029 if you are 17, 18 or 19). The coefficient value equal to 0.0271 means that the probability of university participation rises by 0.0271 if you are female rather than male or, if you prefer, you could say that the percentage of females participating in university is $2.71 \%$ higher than for males.

In the second row of results in Table 2, the estimated model incorporates the zero-one variable called ELIGIBLE presented earlier. Recall that if the respondent's highest educational attainment is reported as $0-8$ years of school (before or after 1990); 9 or 10 years of school before 1990; or after 1990 as some secondary education but not a Grade 11 to 13 graduate, then this respondent is extremely unlikely to be academically eligible for university. The value of ELIGIBLE was set equal to zero. Some of these respondents with the value of ELIGIBLE equal to zero are also currently full-time high students. For everyone else in the data set, 


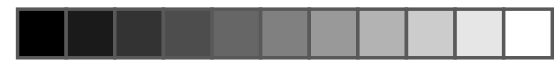

118 D.R. Johnson, \& F.T. Rahman

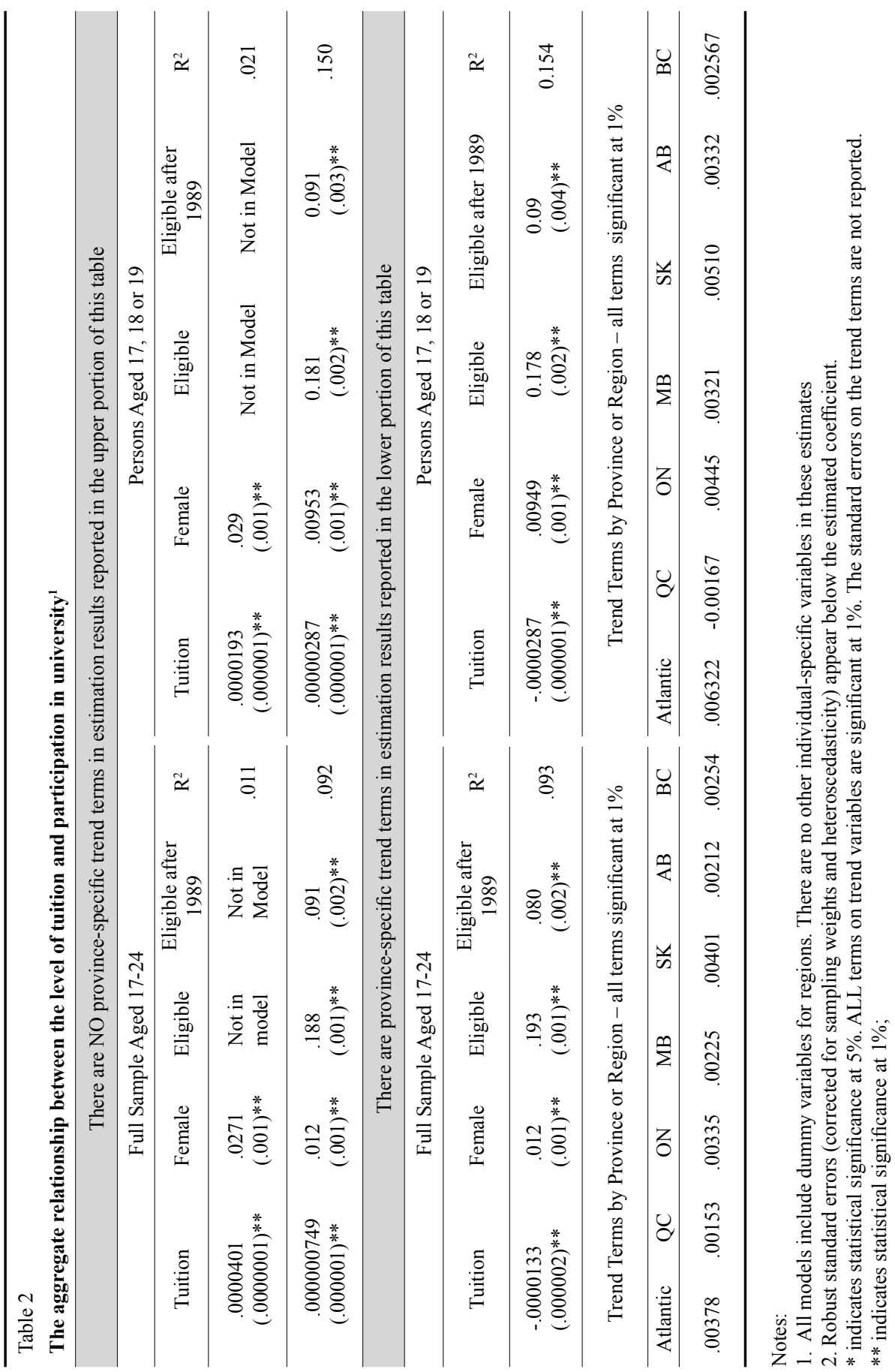

The Canadian Journal of Higher Education

Volume XXXV, No. 3, 2005 


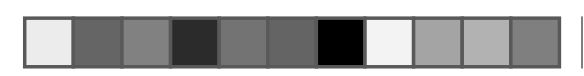

the value of ELIGIBLE is set equal to one. However not all those people would actually be eligible for university either before or after 1990. Some would, even if they had graduated from high school, not have grades to allow admission to a university. Just as importantly, the meaning of the dummy variable called ELIGIBLE changes abruptly after 1990 . Prior to 1990, a person could have 11 to 13 years of schooling and may or may not have been a high school graduate although the value of ELIGIBLE was set equal to one. After 1990, the value of ELIGIBLE is one only if the person is actually a secondary school graduate. To take this into account, after 1990, the dummy variable ELIGIBLE is interacted with a variable equal to one only after 1990. The coefficient on ELIGIBLE for the full sample including years before and after 1990 is 0.188 (or 0.181 in the younger sample).

Where the value of ELIGIBLE equals one, an individual is much more likely to be a university participant, they are much more likely to be a high school graduate, and then, after 1990, they are a high school graduate. The coefficient on the interaction variable, the product of ELIGIBLE and a dummy variable set equal to one after 1990 is 0.091 . When the measure of eligibility is more precise after 1990, the coefficient on ELIGIBLE is much larger, $0.188+0.091$ for the full sample and $0.181+0.091$ for the younger sample. The $\mathrm{R}^{2}$ in the two equations including the eligibility variables are extraordinarily high for regressions using individual data. Changes in high school participation and graduation rates over time are an important part of the university participation story in Canada. ELIGIBLE and the interaction variable capture those changes and then allow us to look for the effects of other economic variables. The analysis was extended by including measures of the opportunity cost, the payoff, and the unemployment gap between high school and university graduates and the support variables to the model of university participation (data not shown in tabular form $)^{20}$. The general pattern and magnitude of the coefficients estimating the effect of tuition on university participation seen in Table 2 was repeated. The tuition variable is interacted with the age variable, that is, the effect of tuition on participation is allowed to vary by age group. In the resulting equations, the age variables are also interacted with the regional dummies. Being 18 in a jurisdiction where high school ends at Grade 12 is different than being 18 in a jurisdiction where high school ends at Grade 13 or in Grade 11. The coefficients on the tuition variables are usually negative. 
The effect is much stronger for persons aged 17, 18 or 19 than for older potential participants. The younger participants are more likely making the decision to start university while the older potential participants would be making the decision, if already in university, to stop. Persons in the older sample will already have a degree and count as participants. The impact of an increase in tuition in the current year on their participation status is zero. The tuition variable is scaled in 1992 dollars. A one thousand dollar increase in tuition was found to lower the probability that a 17, 18 or 19 year old of either gender is a university participant by .012 or $1.2 \%$ in the model without the support variable estimated with data from 1976 to $2003 .^{21}$ If the model is estimated over a shorter time period to 2001 and includes the support variable, the estimated coefficient is a little bit larger. Subsequent analysis restricted the data to males and then to females, respectively. The coefficients on the tuition variable, again for the youngest age group, remain negative, statistically significant and in the same order of magnitude. It is larger (in absolute value) when estimated using the female only sample. There is a statistically significant effect of tuition on participation. ${ }^{22}$ As already discussed, the policy significance of these coefficients is open to considerable dispute.

The opportunity cost variable was then introduced. Its scaling is also in thousands of 1992 dollars. Again it is interacted with age variables. The coefficients are usually negative although not always significantly different from zero. Their estimated values are one order of magnitude less than the size of the coefficient on tuition in the same specification. Thus even when they are statistically significant, they are of less economic significance. There is a difference in the response of individuals to tuition costs and opportunity costs. The next two variables in the model are measures of the benefit of obtaining a university degree.

As with the tuition and opportunity cost variables, they are interacted with the age dummies. The payoff variable is scaled as the ratio of the median wage for those with a university degree compared to those with a high school graduation diploma. A value of 100 would indicate the two groups had the same median wage. The initial analysis showed that the payoff variable was always higher for females than for males. Where both genders are included in the sample the female dummy is "replaced" by the payoff variable. It is impossible to distinguish the effect of being female in Canada from the effect of having a higher payoff to university

The Canadian Journal of Higher Education Volume XXXV, No. 3, 2005 


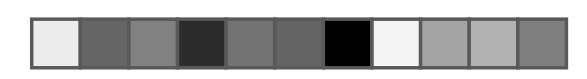

attendance. ${ }^{23}$ A higher payoff is associated with being female. Only one of the two variables, a female dummy or payoff, can enter a model. The positive coefficient on the female variable and the positive coefficients on the payoff variables are closely related. This is one reason why model estimates for males and females are conducted separately. The payoff variable then remains in the model but varies only over time for the relevant gender. The coefficients on the payoff variables are now usually not statistically different from zero and often have the incorrect sign. ${ }^{24}$ There is little variation in the payoff for females over time. There is a modest increase in the payoff for male degree-earners over time. However, the variation over time is still relatively small. There is also no regional variation in this measure of the benefit of university attendance. The second measure of the benefit of university participation does have substantial regional variation.

The second measure of the benefit of university attendance was presented in Figure 2. The gap, in percentage points, between the unemployment rate of persons aged 25-35, by gender, with a university degree and with a high school diploma was calculated for each year and each region. The coefficient on the expected unemployment variable is of the expected sign and is often of statistical significance. The effect appears to be strongest in the entry-level age group. An increase in the unemployment rate gap of 1 percentage point appears to increase the probability of university participation by about .002 or 0.2 percent. Young persons go to university to avoid higher unemployment rates in their future.

As noted in Section 3, the support variable is both very crude, and not available in the last two years of the data. The solution to this problem was to estimate the models of participation with and without the support variable. The regressions estimated with the support variable use two fewer years of data The coefficients on the four other economic variables, tuition, opportunity cost, the payoff and the unemployment rate gap, are reasonably stable to the addition of the support variable and the consequent shortening of the sample by 2 years. The support variable does have a sign which is usually positive and sometimes of statistical significance. University participation rates are higher in regions where more university expenditure is devoted to student support. The measures of student support used in this paper, and in other papers in the literature, are too crude to say much more. 


\section{CONCLUSIONS}

This analysis of university participation using the Labour Force Survey contributes to our understanding and measurement of the effects that increases in real tuition and changes in other economic variables have had on university participation decisions. Increases in tuition have been large in most provinces since 1990. Using the LFS has advantages and disadvantages. Its main disadvantage is the lack of individual background data on important factors like family income or parental education. We know these factors matter. Its main advantage is a very long and very large sample with information on academic eligibility of respondents.

It is very clear that province-specific time trend variables play an important role in describing the increase in the probability of university attendance over time in various provinces. These trend variables must proxy for a wide variety of variables, both economic and non-economic. The empirical results point to three economic factors that increased the probability of university participation between 1976 and 2003: a higher payoff (strongly associated with being female) to university attendance; a lower opportunity cost of university attendance; and a reduction in the probability of unemployment if a person obtains a university degree. Even when these factors are taken into account, province-specific trend variables have significant positive coefficients that measure the increase in the probability of university participation. Over time university participation has increased for many reasons. Tuition increases did reduce university participation relative to trend. This is an important result. Without knowledge of the social and economic forces behind the trend variable, it is not possible to say whether the large increases in university tuition after 1990 were good or bad policy. What is clear is that, all other factors being the same, university participation would have been higher if the tuition increases had not occurred.

Correspondence information: Dr. David Johnson, Department of Economics, Wilfrid Laurier University, 75 University Avenue West, Waterloo, Ontario, Canada N2L 3C5. djohnson@wlu.ca 519-884-1970.

The Canadian Journal of Higher Education

Volume XXXV, No. 3, 2005 


\section{Notes}

1. As this study was undertaken, Neill (2005) was using the master files of the LFS to undertake a similar but not identical study. Our study is compared to Neill's study in Section 2.

2. Examples include the Survey of Labour and Income Dynamics (SLID) which begins in 1993 and the Youth in Transition Survey (YITS) which begins in 2001. These data sources have been used in other studies reviewed in Section 2.

3. Data on changes in tuition are based on a calculation using 1992 dollars.

4. Chapman (2006) contains a very clear analysis of these issues.

5. It is a limitation of the paper that college participants are simply treated as non-university participants, that is, the persons in the sample are treated as making a two-way choice, university or not-university. This is the usual way the problem is posed in the literature already cited. College would involve the same opportunity cost, a different tuition and a different expected payoff. Data on college tuitions do not extend back to 1976. I am not aware of data on the payoff to college before the Labour Force Survey began collecting wage data in 1997.

6. Data not presented. Data are available from the author on request.

7. Les Robb graciously provided the earlier data from Bar-Or, Burbidge, Magee and Robb (1995). Other similar data are found in Burbidge, Magee and Robb (2002).

8. This may exaggerate the opportunity cost if a student is able to work part time during the 8 months at university. Many students do just that. Neill (2005) presents some data indicating an increase in students working part-time over this period. The measure does not take into account payments from the Employment Insurance system during periods of unemployment

9. Some equations were estimated with and without British Columbia to test the sensitivity of the model to the 1989 spike in wages in British Columbia. There are no important changes in results.

10. As noted in the data appendix, the consumer price index by province only starts in September 1978. Values for 1976, 1977 and the early part of 1978 assumed the same inflation rate in all provinces as in Canada as a whole. 
11. Neill (2005) and Coelli (2004) construct similar variables. Junor and Usher (2004) contains an extensive discussion of the difficulty in constructing measures of student support in Canada.

12. There could be exceptional circumstances in which such an individual was admitted as a mature student or into a particular program.

13. This describes a linear trend. Results are not sensitive to addition of a quadratic trend.

14. Coelli (2004) has similar trend variables. Neill (2005) has year fixedeffect variables.

15. The responding households currently remain in the LFS for 6 months on a rotating basis, that is, in each month, one-sixth of the households leave. By using the October survey of each year, the issue of repeating individuals within any 12-month period is avoided.

16. Results using logit or probit models are also available. The results are similar.

17. In the appendix there is a complete list of the individual variables that comprise the elements of vector $\mathrm{X}$.

18. It is this assumption that is relaxed by Neill (2005) with the presentation of instrumental variable estimates of coefficients in equations similar to (1). Coelli (2004) adds some measures of capacity in the university and college system which moves the interpretation of equation (1) from a decision by individuals to a reduced form. The models we estimate could also be interpreted as reduced form models in this sense if the province-specific trend or dummy variables represent capacity constraints that are either systematic by province or change systematically over time.

19. A good introduction to this material is found in Deaton (1997, Chapters 1 and 2) as well as in the Stata Version 8 documentation. The models are estimated using the svyreg command incorporating the survey weights and calculating the necessary robust standard errors allowing for generalized heteroscedasticity. There is a third possible econometric complication. Although the model already contains province-specific fixed effects and province-specific trends, it is possible that the observations within a province constitute a cluster of data where there is correlation within the error terms for the observations within the provincial cluster. Results from estimating equation (1) where the standard errors were adjusted to take this clustering into account were

The Canadian Journal of Higher Education

Volume XXXV, No. 3, 2005 
estimated and are available on request. The standard errors on the coefficients on the tuition variables of primary interest do generally increase but the coefficient estimates remain statistically different from zero at similar levels of statistical significance. The standard errors on the other economic variables generally increase. Fewer of these coefficients are statistically different from zero. A useful discussion of clustering is found in UCLA Academic Computing Services (2005).

20. Data available from the author.

21. If the relationship between university participation and tuition is estimated with a probit model, and one calculates at the means of the independent variables the reduction in the probability of enrolment with an increase in tuition from 2000 (1992) dollars to 3000 (1992) dollars, the point estimate of the reduction in the probability of university participation lies between $0.41 \%$ and $0.73 \%$ depending on the specification. The $95 \%$ confidence interval for these point estimates includes the $1.2 \%$ figure. In the probit model the change in probability is quite similar for a 1000 dollar decrease in real tuition from 2000 to 1000 (1992) dollars). The probit model generates similar results to the linear probability model.

22. This statement continues to be true when the standard errors increase and the provinces are treated as clusters.

23. The simple correlation between the female dummy and the payoff variable is 0.96 .

24. Rathje and Emery (2002) point out that the private payoffs to university attendance are very large in Canada. Thus the variation over time in the variables is quite small relative to the huge return to university attendance in all years for both genders. This could account for the insignificance of the coefficient on the payoff variable in the models estimated separately for males and females, respectively. 


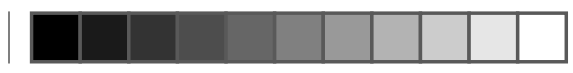

\section{REFERENCES}

Bar-Or, Y., Burbidge, J., Magee, L., \& Robb, A.L. (1995). The Wage Premium to a University Education in Canada, 1971-1991. Journal of Labor Economics 13 (4): 762-794.

Burbidge, J., Magee, L. \& Robb, A.L. (2002). The Education Premium in Canada and the United States. Canadian Public Policy 28 (2): 203-216.

Burbidge, J., Magee, L. \& Robb, A.L. (2003). Wages in Canada: SCF, SLID, LFS and the Skill Premium Hamilton, Ontario: McMaster University.

Butlin, G. (1999). Determinants of Post-Secondary Participation. Education Quarterly Review 5(3): 9-35.

Chapman, B. ( forthcoming 2006). International reforms in higher education financing: income related loans. In E. Hanushek \& F. Welch (Eds.), The Handbook of the Economics of Education. Amsterdam: North-Holland.

Christofides, L.N., Cirello, J. \& Hoy, M. (2001). Family Income and PostSecondary Education in Canada (1975-1993). The Canadian Journal of Higher Education 31(1): 177-208.

Coelli, M. (2004) Tuition Increases and Inequality in Post-Secondary Education Attendance. Vancouver, British Columbia: University of British Columbia.

Corak, M., Lipps, J., \& Zhao, J. (2003) Family income and participation in post-secondary education. Ottawa, ON: Statistics Canada: Analytical Studies Branch Research Paper Series, Catalogue 11F0019MIE. - No. 210.

Deaton, A. (1997). The Analysis of Household Surveys: A Microeconometric Approach to Development Policy. Baltimore, Maryland: Johns Hopkins Press.

Drolet, M., (2005). Participation in Post-secondary Education in Canada: Has the Role of Parental Income and Education Changed over the 1990's? Ottawa, ON: Statistics Canada Analytical Studies Research Paper Series No. 11F0019MIE No. 243.

Fortin, N. (2005). Rising Tuition and Supply Constraints: Explaining CanadaU.S. Differences in University Enrolment Rates. In C.M. Beach, R.W. Boadway \& R.M. McInnis (Eds.) Higher Education in Canada. Kingston, Ontario: John Deutsch Institute.

Frennette, M. (2005). Access to College and University: Does Distance to School Matter? Canadian Public Policy 30 (4): 427-443.

Greene, W.H. (2003). Econometric Analysis, Fifth Edition. Upper Saddle River, New Jersey: Prentice-Hall.

The Canadian Journal of Higher Education Volume XXXV, No. 3, 2005 
Heller, D. E. (1997). Student price response in higher education: An update to Leslie and Brinkman. Journal of Higher Education 68 (6): 624-659.

Heller, D.E. (1999). The Effects of Tuition and State Financial Aid on Public College Enrollment. The Review of Higher Education 23 (1): 65-89.

Junor, S. \& Usher, A. (2002). The Price of Knowledge: Access and Student Finance in Canada. Montreal, Quebec: Canada Millennium Scholarship Foundation Research Series.

Junor, S. \& Usher, A. (2004). The Price of Knowledge: Access and Student Finance in Canada. Montreal, Quebec: Canada Millennium Scholarship Foundation Research Series.

Kennedy, P. (2003). Guide to Econometrics, Fifth Edition. Boston, MA: MIT Press.

Leslie, L.L. \& Brinkman, P.T. (1988). The economic value of higher education. New York, New York: American Council of Education, MacMillan.

Levin, B. (1990). Tuition Fees and University Accessibility. Canadian Public Policy 16 (1): 51-59.

Looker, E.D. \& Lowe, G.S. (2001). Post-Secondary Access and Student Financial Aid in Canada: Current Knowledge and Research Gaps. Canadian Policy Research Network. http://www.cprn.ca/cprn.html

Neill, C. (2004). The impact of tuition fees on the demand for university places. Toronto, Ontario: University of Toronto.

Rathje, K.A. \& Emery J.C.H (2002). Returns to University Education in Canada Using New Estimates of Program Costs. In Laider, D.E.W (Ed.) Renovating the ivory tower: Canadian universities and the knowledge economy. Toronto, Ontario: C.D. Howe Policy Study No. 37.

Rivard, M. \& Raymond, M. (2004). The Effect of Tuition Fees on PostSecondary Education in Canada in the late 1990's. Ottawa, Ontario: Department of Finance Working Paper 2004-9.

Stata Corporation (2003). Stata Release 8. College Station, Texas: The Stata Press

Tomkowicz, J., Shipley, L. \& Ouellette, S. (2003). Perception of Barriers to Education in a Group of 18-20 Year-Olds: For Whom Does Money Matter? Paper presented at the Canadian Employment Research Forum, June 2003.

UCLA Academic Technology Services (2005) Stata Library: Analyzing Correlated Data. http://www.ats.ucla.edu/stat/stata/library/cpsu.htm 